"NOTICE: this is the author's version of a work that was accepted for publication in Computational Materials Science. Changes resulting from the publishing process, such as peer review, editing, corrections, structural formatting, and other quality control mechanisms may not be reflected in this document. Changes may have been made to this work since it was submitted for publication. A definitive version was subsequently published in COMPUTATIONAL MATERIALS SCIENCE, VOL 58, JUNE 2012, PAGES 131-139, DOI: 10.1016/j.commatsci.2012.02.009”

\title{
Numerical analysis of the effect of weld-induced residual stress and plastic damage on the ballistic performance of welded steel plate
}

\author{
E.A. Flores-Johnson*, O. Muránsky, C.J. Hamelin, P.J. Bendeich, L. Edwards \\ Institute of Materials Engineering, Australian Nuclear Science and Technology Organisation \\ Locked Bag 2001, Kirrawee DC, NSW, 2232 Australia
}

\begin{abstract}
The current paper presents numerical analyses that elucidate the effects of post-weld residual stress and associated plastic damage on the ballistic performance of 316L austenitic steel plate. Impact simulations of an 18-mm thick plate with a centreline three-pass slot weld by hemisphericalnosed and flat-nosed projectiles are performed, with initial velocities in the range of 300-800 m/s. The numerical framework consists of three interdependent stages: (i) a weld model was developed in Abaqus/Standard and validated using two independent experimental data sets; (ii) a JohnsonCook material model is calibrated and validated along with the shear failure fracture criterion available in Abaqus/Explicit for impact models; and (iii) the weld modelling results were transferred to an impact model built in Abaqus/Explicit, which employs the validated material and fracture models to predict the ballistic performance of welded plate. It is shown that the associated plastic strain damage accumulated during the welding process - and its distribution - has an adverse effect on the ballistic performance. It has also been determined that a fracture criterion that accounts for pre-existing damage in the weldment must be used for accurate impact analyses of welded structures.
\end{abstract}

Keywords: ballistic impact; welded plate; residual stress; post-weld plastic damage; finite element simulation.

*Corresponding author. Tel.: +61 29717 7348, Fax: +61 29717 9225, e-mail: efj@ansto.gov.au 


\section{Introduction}

Residual stresses are self-equilibrating stresses that are present within a structure when no external forces are applied. Typically, material processing and fabrication techniques create a residual stress field in the final component. One of the most undesirable residual stress fields is caused by conventional welding processes for metallic structures, where high tensile residual stresses develop from a permanent misfit between the near-weld region and the rest of the workpiece [1]. These post-weld tensile residual stresses frequently lead to the premature failure of a component, commonly via accelerated crack growth near the weld region [1, 2]. On the other hand, the introduction of compressive residual stresses (e.g. via shot peening) can be beneficial in improving fatigue life of a component by putting the workpiece surface into compression and thus suppressing crack growth [1, 3-5].

The effect of residual stresses on cyclic fatigue life and fatigue crack propagation has been studied for years and it is reasonably well understood [4]; however, virtually no information exists in the available literature regarding the effect of residual stresses on impact performance. Reddy and Mohandas [6] experimentally studied the influence of welding process and residual stress on the ballistic impact performance of high-strength low-alloy ferritic steel, welded by three different welding procedures (i.e. SMAW - shielded metal arc welding, FCUW - flux cored arc welding and GTAW - gas tungsten arc welding). They found that the ballistic performance of the heat affected zone (HAZ) improved in the case of SMAW when compared to FCUW and GTAW; however, the ballistic performance of the parent plate is not reported. This improvement in performance was attributed to the tensile residual stresses aligned with the impact axis opposing projectile penetration, concluding that the residual stress field may be beneficial in certain cases [6]. The present authors are not aware of any other publication in the open literature where a similar impact assessment has been conducted.

The current work presents finite-element (FE) simulations that examine the effect of residual stress and associated plastic damage on the ballistic performance of welded austenitic steel plate. An 18-mm thick plate of 316L steel with a centreline three-pass slot weld designed to mimic a butt weld is impacted by hemispherical-nosed and flat-nosed projectiles, with initial velocities in the range of 300-800 m/s. The present analysis consists of decoupled welding (via Abaqus/Standard) and ballistic (via Abaqus/Explicit) models, whereby the results of the welding simulation (i.e. the residual stress field and post-weld plastic strain) are transferred as input for the impact analysis. The Johnson-Cook material model used for impact simulations is calibrated and validated using published experimental data, and makes use of a validated fracture model available in Abaqus/Explicit - shear failure - to predict the ballistic performance of welded structures.

\section{Welded plate}

A tungsten inert gas (TIG) three-pass weld was made in a 194-mm $\times 450$-mm $\times 18$-mm block of AISI 316L stainless steel, with a centreline machined slot $80 \mathrm{~mm}$ long and $6 \mathrm{~mm}$ deep. After machining the slot, but before welding, the piece was stress relieved by furnace-heating from room temperature to $1050{ }^{\circ} \mathrm{C}$ at $5{ }^{\circ} \mathrm{C} / \mathrm{min}$, held at $1050 \pm 5{ }^{\circ} \mathrm{C}$ for 45 minutes, furnace-cooled to $300{ }^{\circ} \mathrm{C}$, and then air-cooled to room temperature. The slot was then filled with three subsequent weld passes via automated TIG welding, using 0.9-mm ER316L filler wire (Fig. 1). The specimen was welded free of restraint so that the plate would distort without inhibition; this condition resulted in a bending distortion of approximately \pm 0.8 degrees about the weld line (denoted the 3 -axis in FE simulations), and a bending distortion of approximately 0.4 degrees about the transverse weld axis 
(denoted the 1-axis). The specimen was extensively instrumented during the welding process, with a number of thermocouples at various locations to capture the cyclic thermal history of the welding process for FE model input [7].

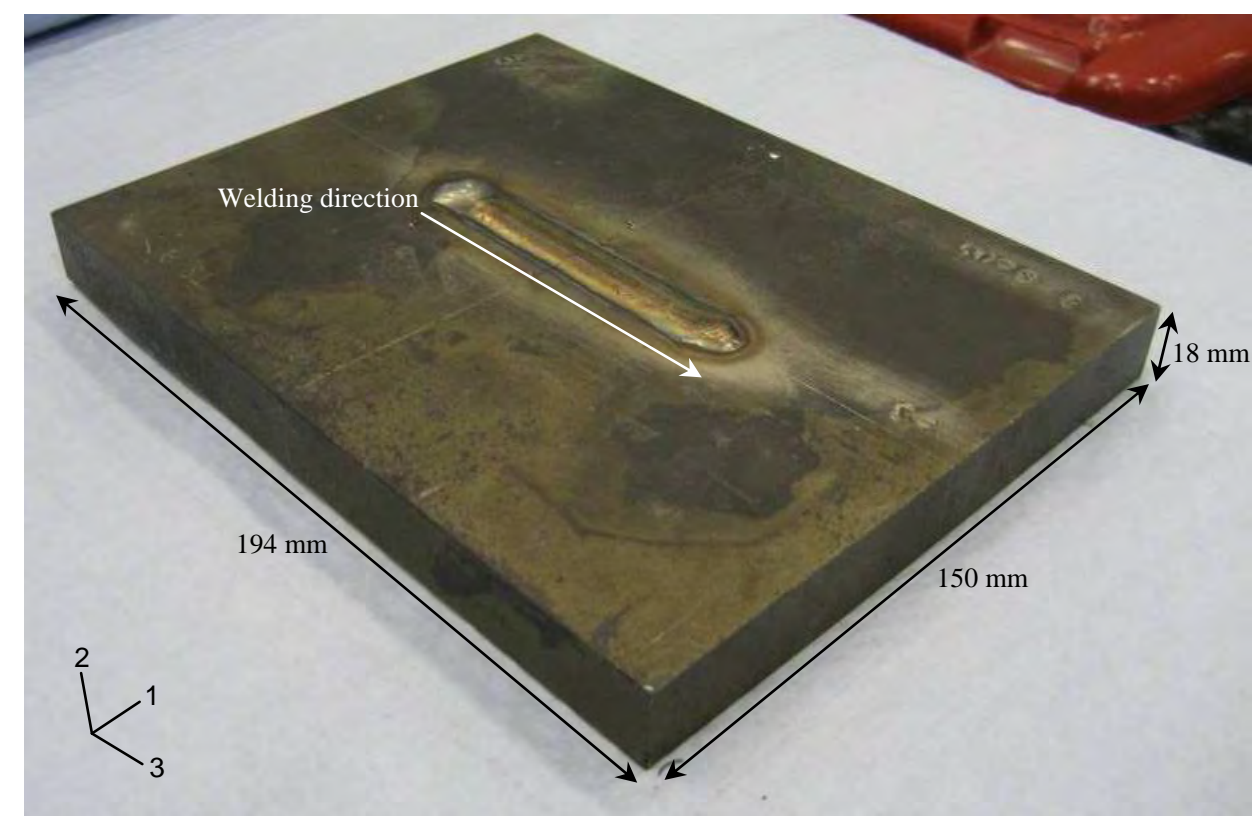

Figure 1. Three-pass slot weld sample.

\section{Finite element modelling}

FE simulations were performed using Abaqus 6.9 [8]; a representative half-model of the weldment was developed in Abaqus as shown in Fig. 2a, assuming a symmetry axis about the weld centreline to reduce computational expense. The current FE analysis was split into three stages: in the first stage, a thermo-mechanical weld model was developed in Abaqus/Standard, due to the verified accuracy of FE weld simulations using an implicit formulation [9, 10] and validated using two independent diffraction techniques; in the second stage, Johnson-Cook model parameters are determined using high strain-rate and elevated-temperature test data and validated using ballistic impact experimental data; and in the third stage the post-weld residual stresses and associated plastic damage from the weld model in Abaqus/Standard were imported to an impact model built in Abaqus/Explicit, which employs the calibrated and validated Johnson-Cook material model and a shear failure (SF) fracture criteria to capture the projectile-weldment interaction (Fig. 2b).

\subsection{Weld model in Abaqus/Standard}

Because a comprehensive overview of the weld model development and validation is presented elsewhere [9], only a brief description of this analysis is included here. A 3D half-model comprising 38220 hexahedral quadratic elements was built using Abaqus CAE (see Fig. 2a). The weld simulation was decoupled into consecutive thermal and mechanical analyses, whereby the thermal history predicted by the thermal analysis is used as input for the subsequent mechanical analysis. Since the plate (AISI 316L) and filler (ER316L) material differ only in the Cr content, the same thermal, thermo-physical and mechanical properties were assumed for both the parent metal (plate) and the weld metal. Additionally, because the plate-parent and filler-weld materials are austenitic steels, no solid-state phase transformation was required for the numerical solution. 
A detailed record of the welding parameters (i.e. torch settings) and thermocouple data allowed for an accurate pass-by-pass calibration of the moving-heat-source, performed using the dedicated weld heat source modelling tool FEAT-WMT [11]. Transient body heat flux data determined using FEAT-WMT is then used as input for the mechanical weld model, where reduced-integration stress elements (C3D20R) are used instead of heat transfer elements (DC3D20) to capture the constitutive response of the weldment. Due to the strong cyclic hardening of AISI 316L, mixed isotropickinematic work hardening data was specified for the material in Abaqus. This predicted behaviour was fitted to empirical data via a Lemaitre-Chaboche hardening model [12, 13] that allows simulation of both the Bauschinger effect and cyclic hardening with plastic shakedown, which are both important phenomena during welding [10].

The post-weld residual stress field predicted via the mechanical model were validated against neutron diffraction [9] and spiral-slit synchrotron [14] measurements of the weldment, with good agreement found. These stresses and the associated plastic strain field were subsequently mapped onto an optimised impact model in Abaqus/Explicit. This second FE mesh (Fig. 2b) does not include the weld cap, as in real structures this is usually removed prior to service. Figure 3 shows the residual stress and plastic strain distributions from the thermo-mechanical model and the optimised impact model. Comparison of these models shows that both the cap removal process and the interpolation required for inconsistent mesh geometries does not affect the predicted post-weld stress/strain fields during mapping.

(a)

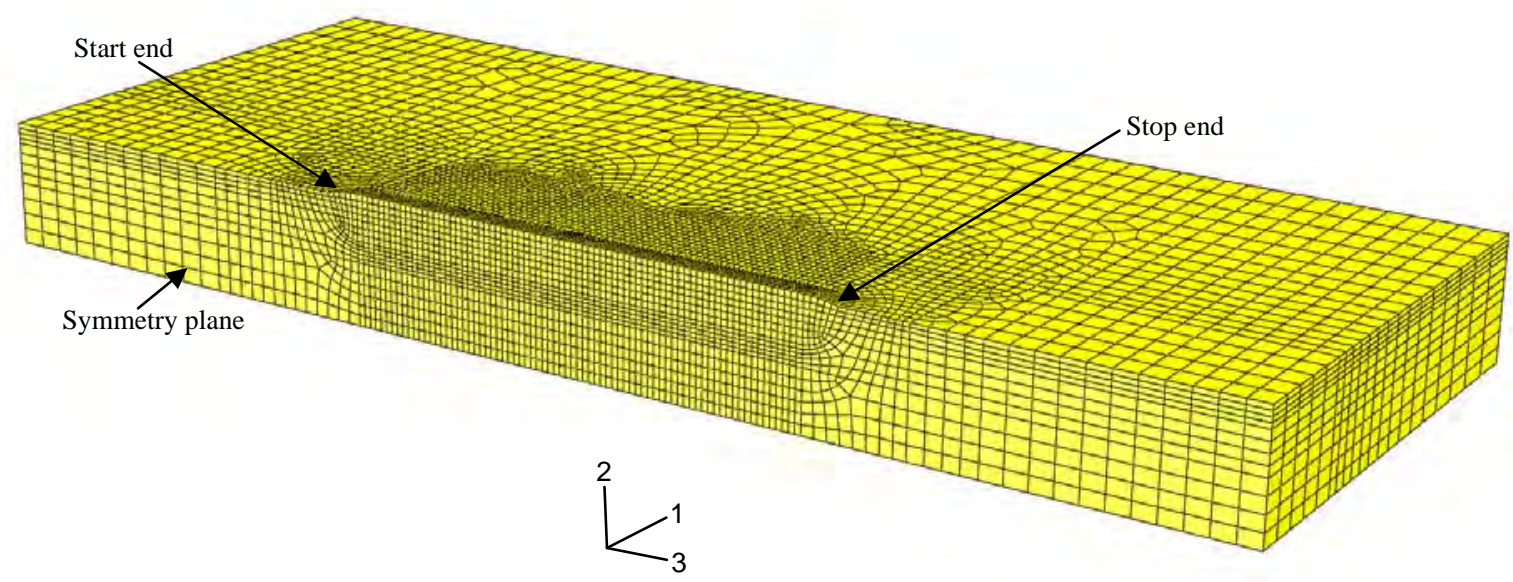

(b)

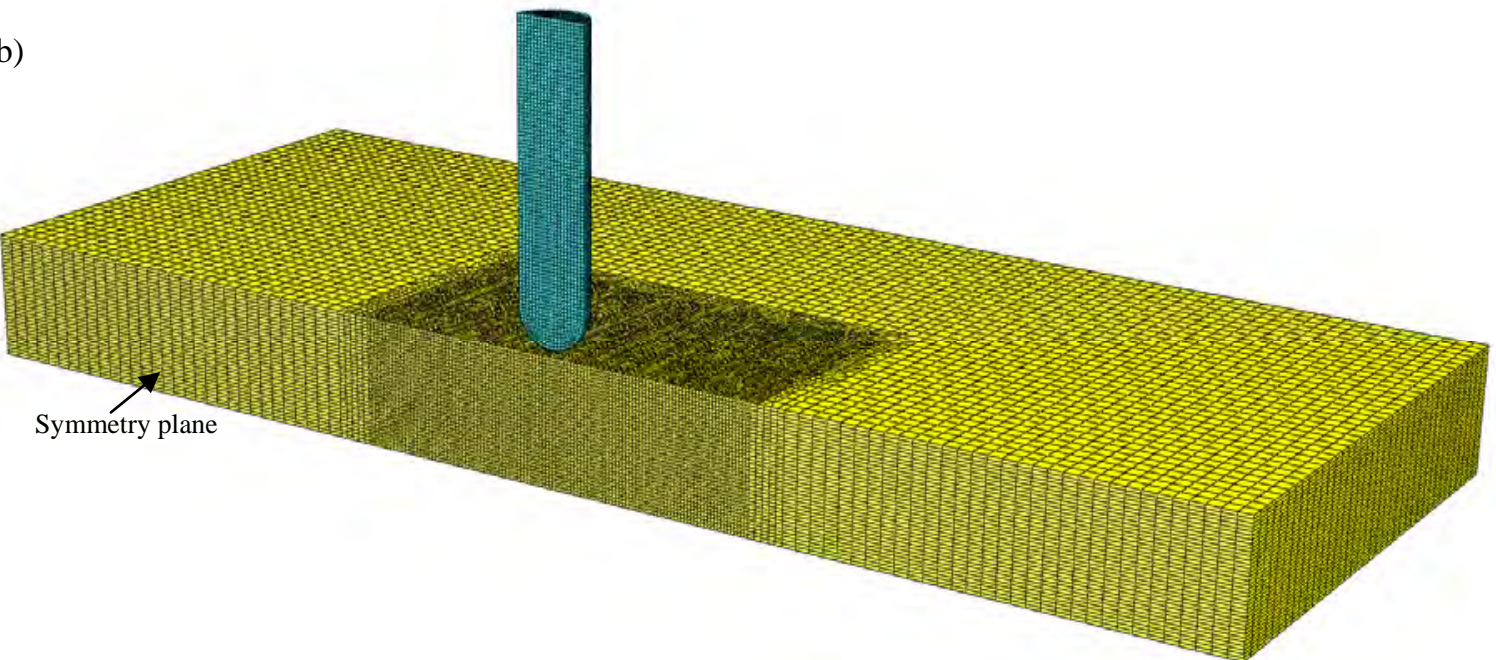

Figure 2. Finite element models developed in Abaqus/Standard: (a) the thermo-mechanical weld model; and Abaqus/Explicit: (b) the impact model. 
(a)

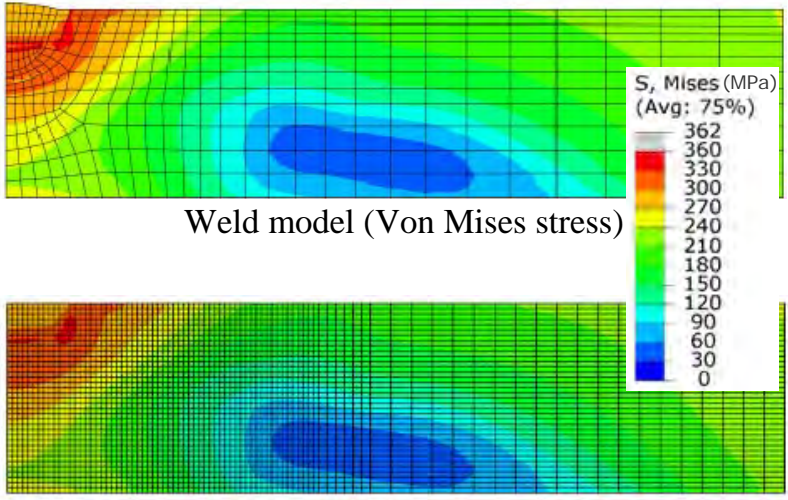

Impact model (Von Mises stress) (b)

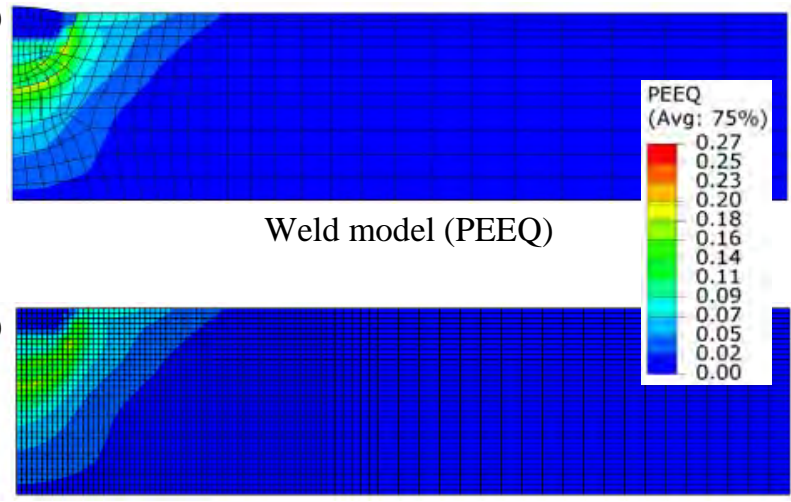

Impact model (PEEQ)

Figure 3. Original mesh cross-section from the thermo-mechanical weld analysis: (a) stress profile; and (b) plastic strain profile. Refined mesh cross-section (with weld cap removed) for impact analysis, after mapping: (c) stress profile; and (d) plastic strain profile.

\subsection{Calibration and validation of constitutive response for impact models}

The explicit numerical model used for impact simulation requires both a material model and a fracture criterion. The Johnson-Cook material model [15] was used to predict the behaviour of the target, while the SF fracture criterion available in Abaqus/Explicit is considered in this work. An overview of each formalism is provided below, followed by a summary of the calibration and validation processes used for each.

\subsubsection{Johnson-Cook constitutive model}

The Johnson-Cook constitutive model [15] is an empirical model, expressed as:

$$
\sigma_{e q}=\left(A+B \varepsilon_{e q}^{n}\right)\left(1+C \ln \dot{\varepsilon}_{e q}^{*}\right)\left(1-T^{* m}\right),
$$

where $\sigma_{e q}$ is the equivalent stress; $\varepsilon_{e q}$ is the equivalent plastic strain; $\dot{\varepsilon}_{e q}^{*}=\dot{\varepsilon}_{e q} / \dot{\varepsilon}_{0}$ is the dimensionless plastic strain rate, where $\dot{\varepsilon}_{e q}$ and $\dot{\varepsilon}_{0}$ are the strain rate and a user-defined strain rate, respectively; and $A, B, n, C$ and $m$ are material constants. The homologous temperature $T^{*}$ is defined as $T^{*}=\left(T-T_{r}\right) /\left(T_{m}-T_{r}\right)$, where $T$ is the absolute temperature, $T_{r}$ is the room temperature and $T_{m}$ is the melting temperature.

\subsubsection{Shear failure (SF) fracture criterion}

The shear failure (SF) fracture model is based on the accumulated equivalent plastic strain in an element, as defined by [8]:

$\omega=\frac{\varepsilon_{e q}^{0}+\sum \Delta \varepsilon_{e q}}{\varepsilon_{f}^{J C}}$,

where $\omega$ is the damage parameter; $\varepsilon_{e q}^{0}$ is the initial (i.e. pre-existing) value of the equivalent plastic strain; and $\varepsilon_{f}$ is the Johnson-Cook fracture strain, which is given by [16]:

$\varepsilon_{f}^{J C}=\left(D_{1}+D_{2} \exp \left(D_{3} \sigma^{*}\right)\right)\left(1+D_{4} \ln \varepsilon_{e q}^{*}\right)\left(1+D_{5} T^{*}\right)$, 
where $D_{1}, \ldots, D_{5}$ are material constants and $\sigma^{*}=\sigma_{m} / \sigma_{e q}$ is the stress triaxiality where $\sigma_{m}$ represents the hydrostatic stress. Material failure is predicted when $\omega \geq 1$. The SF fracture criterion is used for element erosion in conjunction with the Johnson-Cook material model.

\subsubsection{Johnson-Cook material model calibration}

The procedure used by Dey et al. [17] to calibrate the material parameters of the Johnson-Cook material model was followed. The parameters $A, B, C, n$, and $m$ from Eq. 1 were fitted using experimental data acquired during quasi-static uniaxial tensile tests at various temperatures [18] and strain rates [19], shown in Fig. 4. The parameter $A$ was designated the $0.2 \%$ offset yield stress at room temperature $\left(23^{\circ} \mathrm{C}\right)$, allowing the parameters $B$ and $n$ to be fitted to the same monotonic stress-strain curve. The parameter $C$ was obtained from high strain-rate tests at room temperature (Fig. 4b), while $m$ was determined using elevated-temperature test data (Fig. 4a). The conventional least-squares technique was used for all calibration studies. Johnson-Cook parameters obtained for 316L stainless steel are listed in Table 1, and Fig. 4 presents the predicted material behaviour of 316L using the calibrated Johnson-Cook model, which is in good agreement with both sets of empirical data.
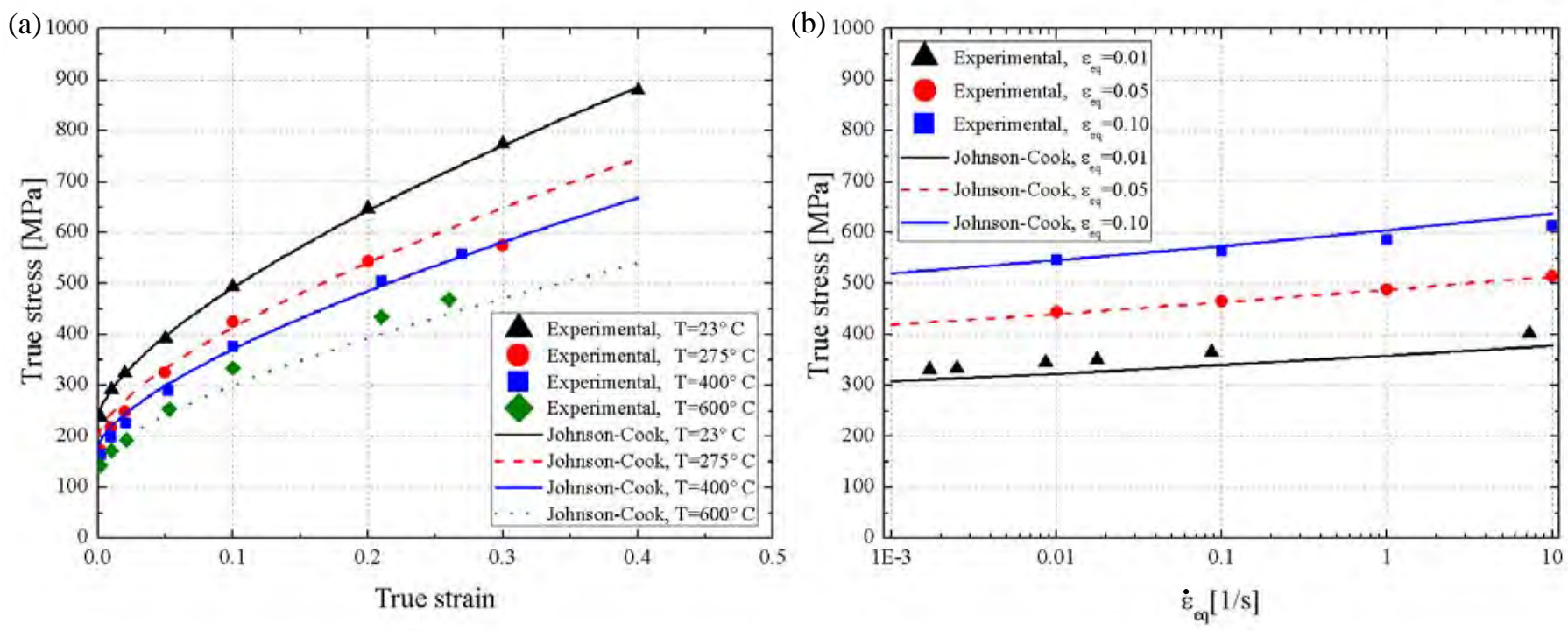

Figure 4. Comparison between experimental and predicted results by the Johnson-Cook material model using the parameters in Table 1: (a) quasi-static tensile test at room and elevated temperatures (Smith and Smith, 2009); and (b) high strain rate tests at room temperature (Nordberg, 2004).

Table 1. Johnson-Cook model parameters for 316L stainless steel.

\begin{tabular}{cccccc}
\hline \multirow{2}{*}{ (MPa) } & $B(\mathrm{MPa})$ & $n$ & $C$ & $m$ & $\varepsilon_{f}^{J C}$ \\
\hline 238 & 1202.4 & 0.675 & 0.0224 & 1.083 & 0.49 \\
\hline
\end{tabular}




\subsubsection{Johnson-Cook material model and fracture criteria validation}

Experimental fracture strain parameter $\varepsilon_{f}^{J C}=0.49$ was obtained from impact studies of 316L plate [20], and used for the SF fracture criteria (Eq. 2 ) in conjunction with the calibrated JohnsonCook material model. An impact model using the calibrated Johnson-Cook model parameters was built in Abaqus/Explicit and validated against experimental observations [20], which consisted of a 12.68-mm flat-nosed (FN) projectile with a mass of $29.9 \mathrm{~g}$ impacting a $0.5-\mathrm{mm}$ thick 316L plate at an initial obliquity of $30^{\circ}$. Good agreement between experiment and simulation is illustrated in Fig. 5 when full penetration is achieved, with a slight underestimation of the ballistic limit (3.3\% less than the lower bound). Figure 6a shows the plate after penetration by the FN projectile; it can be seen that the failure mechanisms observed experimentally (e.g. tensile tearing and hinging) are reproduced by the numerical model, Fig. $6 \mathrm{~b}$. Normal penetration ( $0^{\circ}$ angle of obliquity) of a 12.68mm hemispherical-nosed projectile with a mass of $19.9 \mathrm{~g}$ was also simulated and compared to experimental results [20]. Figure 6c shows the plate after penetration by the HN projectile; it can be seen that the failure mode (i.e. petalling) observed experimentally is reproduced by the numerical simulation, Fig. 6d. The predicted ballistic limit in this study was $117.2 \mathrm{~m} / \mathrm{s}$, which is within the experimental margin of error reported $(125 \pm 12.5 \mathrm{~m} / \mathrm{s})$. The validation of both Johnson-Cook material model and SF fracture criterion permits further impact analyses using the welded plate target.

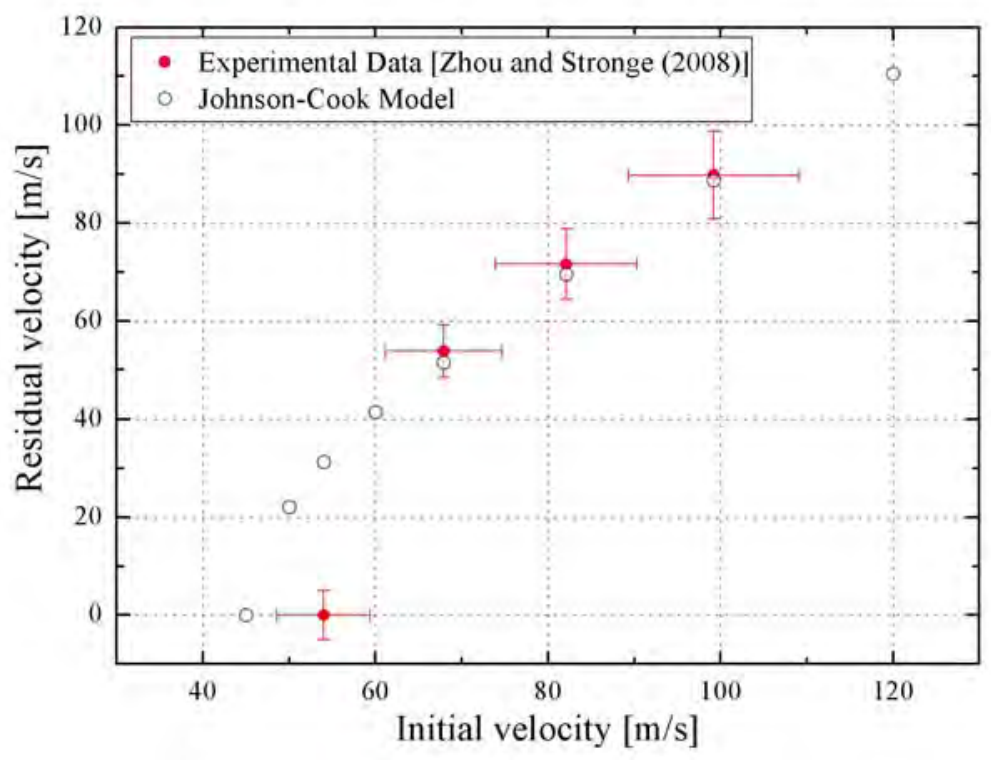

Figure 5. Comparison between experimental and predicted residual velocities for 0.5-mm thick 316L plate impacted by a 12.68-mm flat-nosed nosed projectile with an initial obliquity of $30^{\circ}$ [20].

\subsection{Numerical analyses of impact on welded plate in Abaqus/Explicit}

A refined 3D half-model with 398124 reduced-integration linear hexahedral elements (C3D8R) was built in Abaqus/Explicit (see Fig. 2b), with an average element size of $0.5 \times 0.5 \times 0.5 \mathrm{~mm}^{3}$ in the $\mathrm{i}$ mpact area. Hemispherical-nosed (HN) and flat-nosed (FN) projectiles were used to simulate impac t events; both projectiles were $10 \mathrm{~mm}$ in diameter and had an equal total mass of $25.8 \mathrm{~g}$, resulting in lengths of 43 and $41.25 \mathrm{~mm}$ for the $\mathrm{HN}$ and FN projectiles, respectively. Both projectiles were mod elled as discrete rigid bodies. Three different impact analyses were conducted for each projectile: (i) projectile impact from the weld side of the weldment; (ii) projectile impact from the back face of th e weldment; and (iii) projectile impact with a virgin plate, containing neither residual stresses nor as 
sociated plastic damage. This test matrix was constructed to assess the effect of residual stresses and pre-existing plastic damage on the ballistic performance of welded plate. Impact velocities ranging from $300-800 \mathrm{~m} / \mathrm{s}$ were simulated.
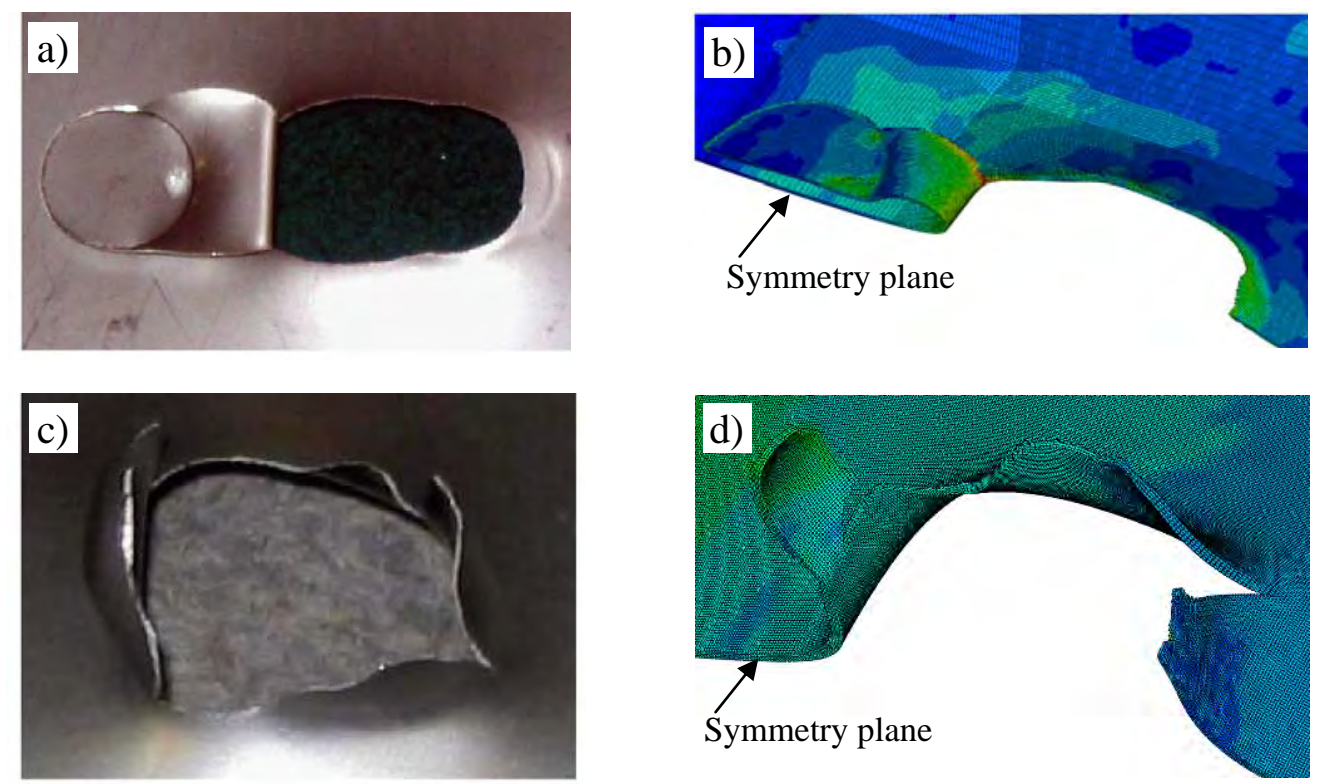

Figure 6. Comparison of failure mode in monolithic 0.5-mm thick 316L steel impacted by a flat-nosed projectile: a) experimental observation (Reprinted from Zhou and Stronge, 2008); and b) numerical solution. Comparison of failure mode using a hemispherical-nosed projectile: c) experimental observation (Reprinted from Zhou and Stronge, 2008); and d) numerical solution.

After mapping the thermo-mechanical weld modelling solution onto the impact model, the material properties, contact definition, and boundary conditions were re-defined for impact studies. Note that the hardening formalism was altered from a mixed isotropic-kinematic hardening model (Lemaitre-Chaboche) used for welding simulations to an isotropic hardening model (Johnson-Cook material model with parameters from Table 1), since the former does not capture the strain-rate dependency of work hardening in the material.

\section{Results and Discussion}

4.1 Weld-induced residual stress and associated plastic damage

Contour plots of the predicted post-weld von Mises residual stresses and associated equivalent plastic strain field (PEEQ) are shown in Fig. 7. The individual stress components in three principal directions are shown in Fig. 8, where S11, S22, and S33 correspond to the transverse, normal, and longitudinal stress components, respectively.

In general, it can be seen in Fig. 7a that a high residual stress field is predicted in the slot weld and the surrounding heat affected zone (HAZ). The stress-field contour map of the transverse crosssection in Fig. 3a reveals that the residual stress field wholly encompasses the weld area. Figure 8a shows that high tensile transverse stresses are predicted beneath the weld bead, as well as alongside the weld bead on the top plate surface, peaking close to the weld stop-end in both cases. High tensile longitudinal stresses are also predicted beneath the slot weld in the HAZ, and in the material applied during the first and second weld pass (Fig. 8c). The normal residual stresses (Fig. 8b) are close to zero throughout the plate as one would expect for this type of sample geometry. The high 
tensile transverse and longitudinal stresses are balanced by compressive stresses that extend towards the sample edges in all three directions (Figs. 8a, c).

(a)

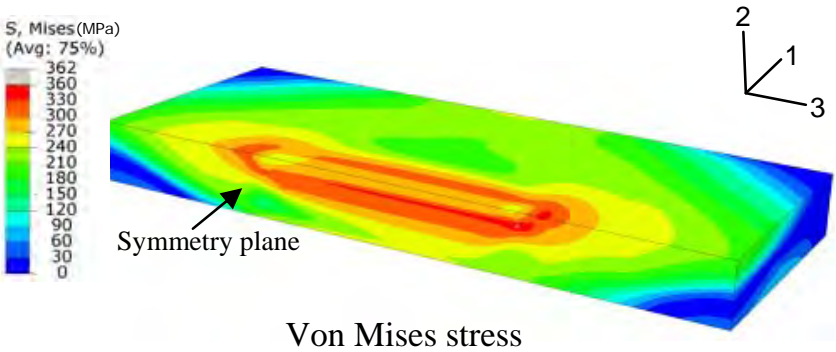

(b)

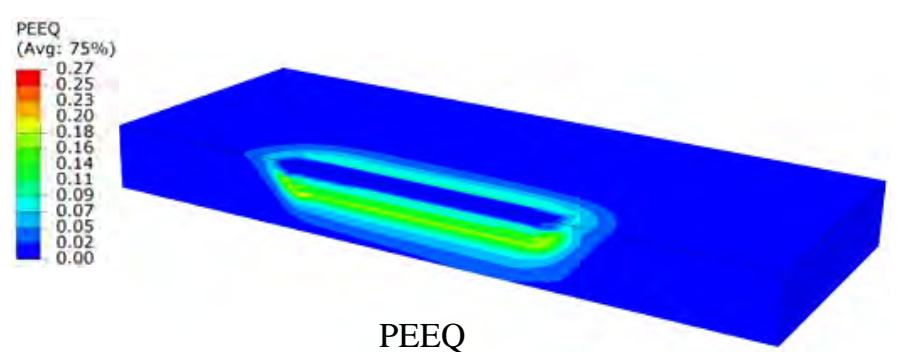

Figure 7. (a) Von Mises and (b) PEEQ from the thermo-mechanical analysis of a three-pass slot-welded plate.

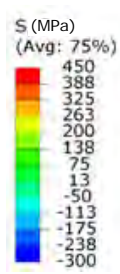

(b)

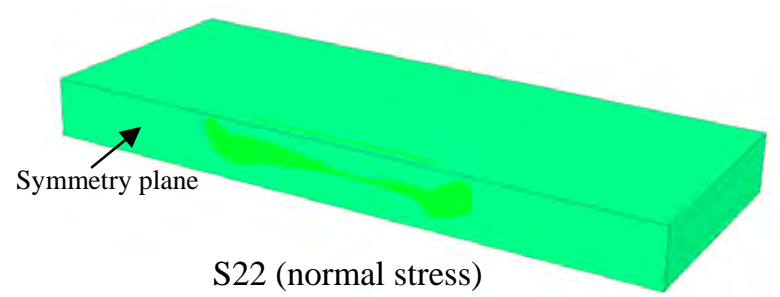

(a)

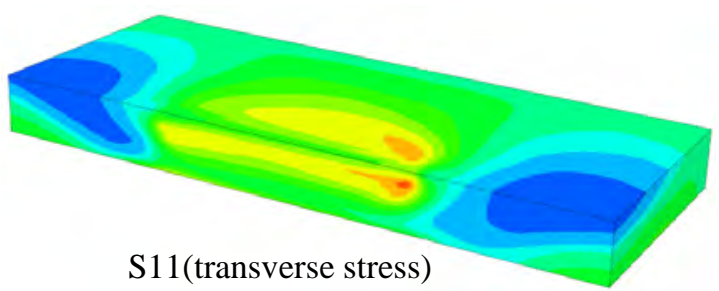

(c)

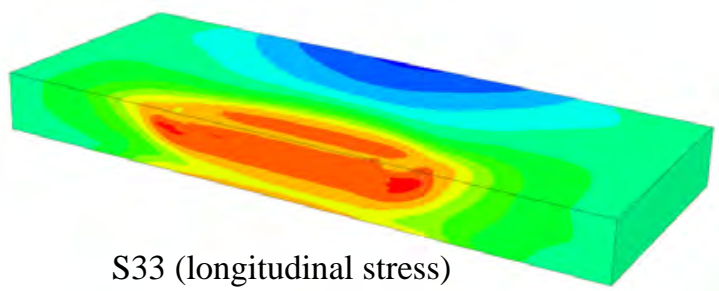

Figure 8. Comparison of (a) transverse, (b) normal and (c) longitudinal stresses in weld plate from the thermomechanical weld analysis.

As previously mentioned, the predicted residual stresses have been validated using two independent diffraction techniques with a high degree of accuracy: neutron diffraction measurements [9, 14] and spiral-slit synchrotron diffraction measurements [9, 14]. These predictions are therefore assumed to be representative of similar GMAW welds found in service, such that the ballistic impact predictions presented are of relevance. Also note that regions of high residual stress are intrinsically connected with the regions experiencing high plastic deformation during the welding process, which is highlighted in Fig. 7; as discussed below, the presence of postweld plastic damage is of primary concern for ballistic analyses of welded plate. 


\subsection{Ballistic impact numerical results}

\subsubsection{Comparison of impact solutions for welded and parent material}

Figures 9a and 9b show the transient weld-side impact predictions of post-weld 316L plate, via hemispherical-nosed (HN) and flat-nosed (FN) projectiles, respectively, under an initial impact velocity of $450 \mathrm{~m} / \mathrm{s}$. By fixing the upper von Mises stress limit to $360 \mathrm{MPa}$ in these studies, it can be seen that the predicted impact zone due to FN penetration (Fig. 9b) is noticeably larger than that produced during HN penetration (Fig. 9a). At $t=70-100 \mu$ s in each solution, the expected perforation mechanism for each projectile can be identified: perforation is dominated by ductile hole growth when the HN projectile is used, while perforation is dominated by shear plugging when the FN projectile is used [17].

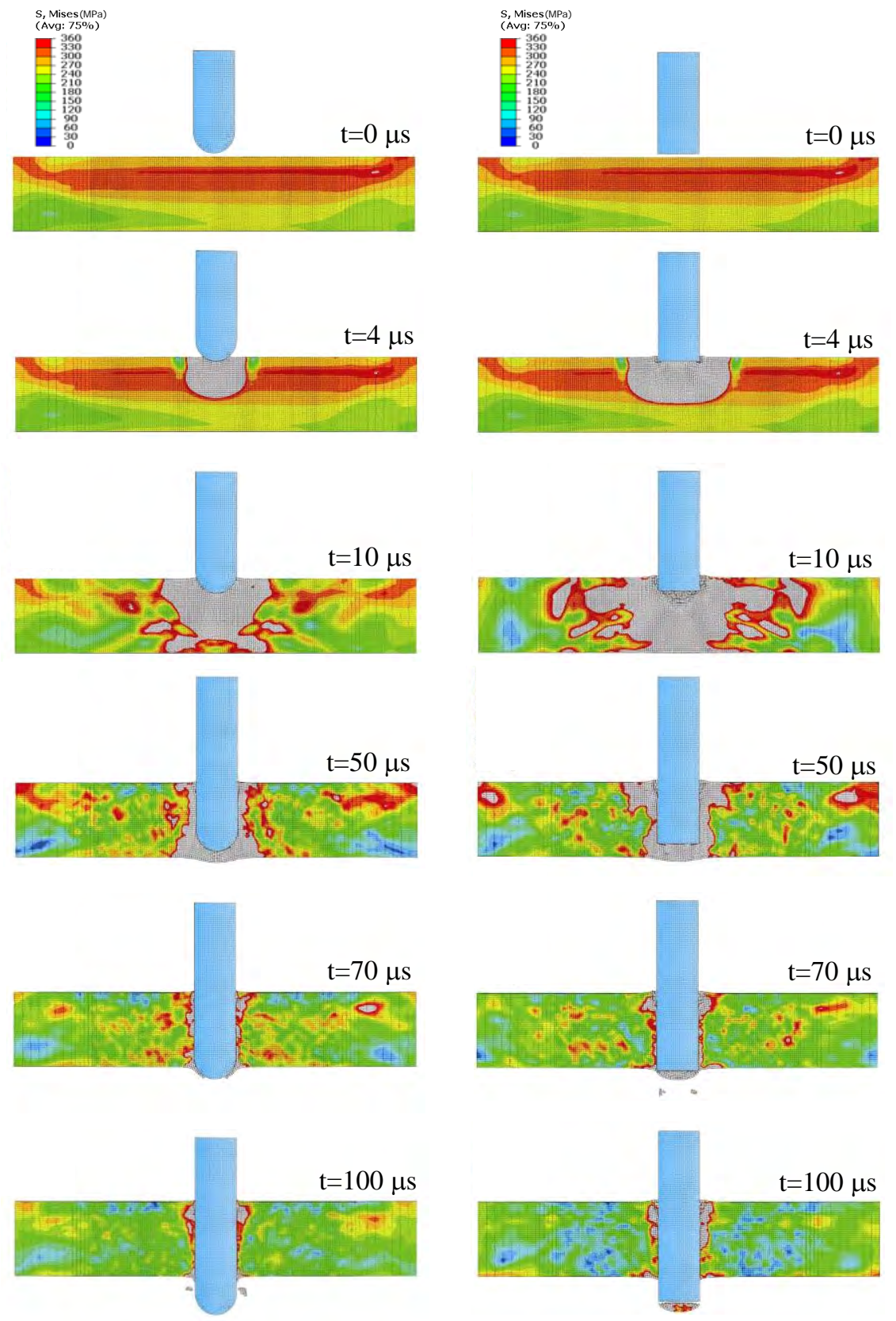

Figure 9. Penetration process of welded 316L plate impacted by: a) a 12-mm hemispherical-nosed (HN) projectile at $450 \mathrm{~m} / \mathrm{s}$; b) a 12-mm flat-nosed (FN) projectile at $450 \mathrm{~m} / \mathrm{s}$. 
Figure 10 plots predicted post-penetration residual velocity versus initial velocity for $\mathrm{HN}$ and FN projectiles. The ballistic performance is evaluated for both the stress-free parent plate and the welded plate; in the case of the latter, studies are conducted of both weld-side and back-face projectile impact.

Numerical solutions for the parent (virgin) plate shows that the predicted ballistic limit is higher for HN projectiles than it is for FN projectiles (Fig. 10), which suggests that more energy is required to push the material aside by plastic work with HN projectiles than via shearing with FN projectiles [21].

In the case of welded plate, a predicted degradation of ballistic properties is observed when compared to the parent plate, including a lower predicted ballistic limit. An increase in the predicted residual velocity for both projectiles is observed for welded plate studies, when compared to parent plate analyses.
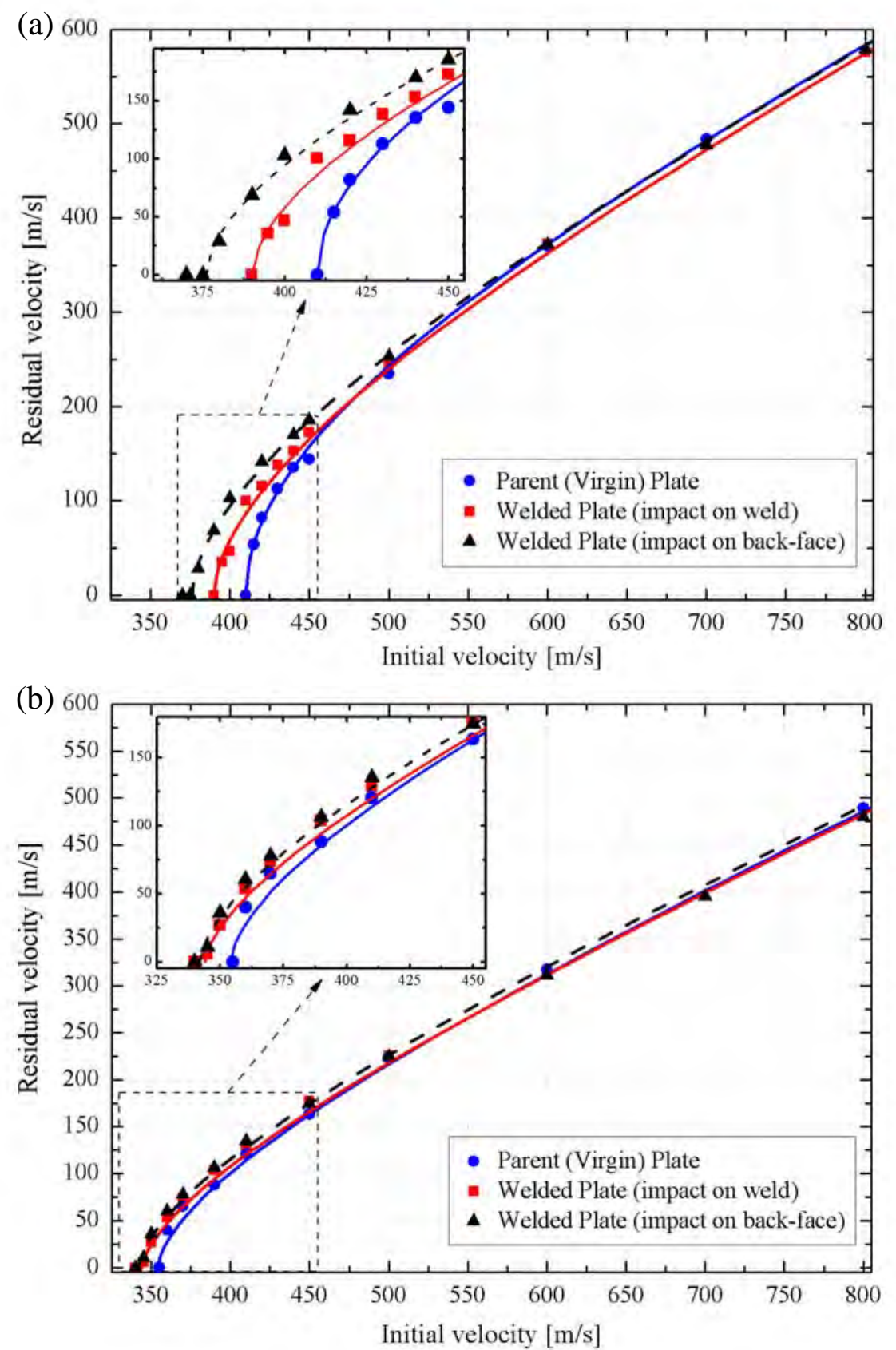

Figure 10. Initial versus residual velocity for parent plate, welded plate impacted on the weld side, and welded plate impacted on the back-face for a) hemispherical-nosed projectiles and b) flat-nosed projectiles. 
Model predictions using the SF failure criterion suggest that the ballistic performance of welded plate is adversely affected by either the post-weld residual stress or plastic damage (or a combination of the two) imparted to the material during the welding process, as evidenced by the lower ballistic limit and higher residual velocities predicted relative to parent plate analyses (Fig. 10). It is clear that the post-weld plastic damage $\varepsilon_{e q}^{0}$ - which is accounted for in the SF fracture criteria (Eq. 2) - degrades the ballistic performance of the weldment.

Figure 11 shows the equivalent plastic strain (PEEQ) versus time for an element in the midsection of specimen for both parent plate and welded plate impacted by either HN or FN projectiles. It can be seen that the element fails when PEEQ reaches the prescribed fracture strain parameter $\left(\varepsilon_{f}^{J C}\right)$ of 0.49 for both the parent plate and the welded plate, and the trends are observed independent of the projectile used (i.e. HN or FN, see Fig. 11).

The adverse effect of post-weld plastic damage can be seen in Fig. 11 for the welded plate, as less impact-related plastic strain can be accommodated in the element prior to failure when compared with the parent plate. Since the amount of energy that the parent material can absorb without fracture (i.e. the toughness of the material) is proportionally decreased by the thermomechanically induced plasticity imparted during the welding process, this pre-existing plastic damage must be considered. While the plastic flow imparted during welding has a beneficial strain hardening effect that increases the yield strength of the deformed metal, it remains that with respect to ballistic performance the negative effect of weld-induced plastic deformation outweighs the positive effect of strain hardening.

It is clear from the present results that a material model with a fracture criterion that takes into account the post-weld plastic damage must be used when predicting the ballistic performance of welded plate. Since the ballistic performance seems to be worsened by the post-weld plastic damage (as per SF failure criteria-based predictions), a comprehensive sensitivity analysis of these parameters to the ballistic performance is recommended. When considering projectile shape, a FN projectile will penetrate both welded and parent plate easier than a HN projectile; furthermore, the difference in the ballistic limit between welded and parent plate is greater for HN projectiles (Fig. 10a) than it is for FN projectiles (Fig. 10b). This phenomenon suggests that the post-weld damage of welded plate has a higher effect on the ballistic performance when the plate fails via ductile hole enlargement, which is associated with the HN projectile perforation.

\subsubsection{Weld-side and back-face impact solutions for welded plate}

Figure 10 includes a comparison of the predicted ballistic performance for welded plate when impacted by hemispherical-nosed (Fig. 10a) and flat-nosed (Fig. 10b) projectiles either on the weld side (top) or on the back face (bottom). The predicted ballistic performance using the SF fracture criterion is worse for back-face impact scenarios than for weld-side impact scenarios for both projectiles; however, it is more pronounced for HN projectiles than for FN projectiles.

This indicates that post-weld plastic damage must be responsible for the orientation-dependent behaviour predicted with the SF fracture criterion. These results further enforce the restriction that accurate predictions of the ballistic performance of welded plate may only be performed when using a fracture criterion that considers pre-existing plastic damage of the target. In addition, a greater variation in weld-side and back-face ballistic limits when using the HN projectile (Fig. 10a) compared to the FN target (Fig. 10b) further supports the earlier claim that ductile hole enlargement 
is dependent on the post-weld plastic damage of the target. Since the total amount of such damage is constant irrespective of the impact direction, the ballistic performance appears to also be dependent upon the damage distribution within the target; Figs. 3 and 7 show post-weld plastic damage to be concentrated on the weld side. From the back-face impact studies presented, the concentrated damage appears to have a notable effect on the ballistic performance of the material as the projectile exits the weld side. Weld-side impact studies show that the lower level of post-weld plastic damage on the back-face improves the overall predicted ballistic performance of the weldment, and is therefore the preferred impact orientation.
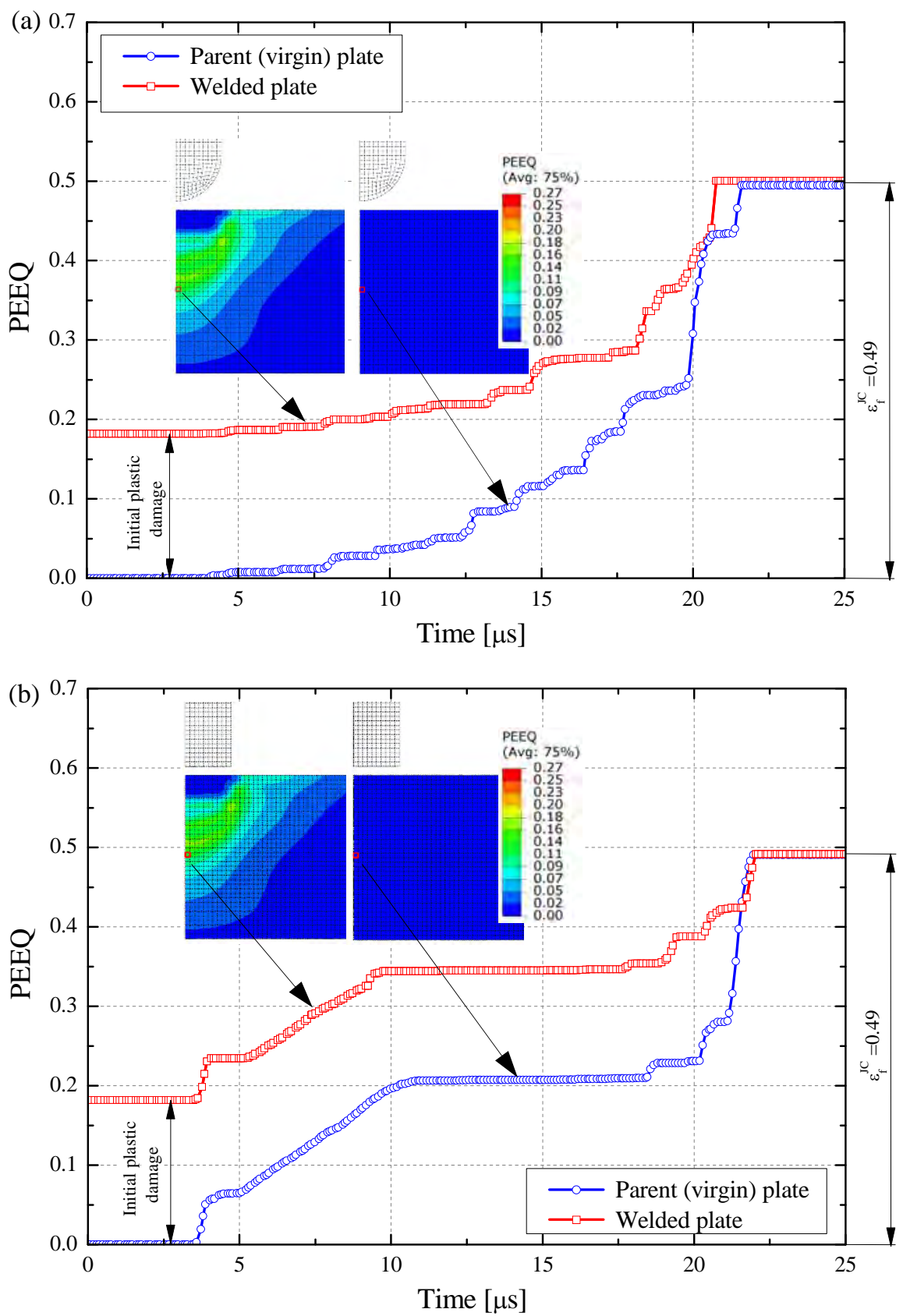

Figure 11. Equivalent plastic strain (PEEQ) versus time for parent (virgin) plate and welded plate impacted on the weld side: a) hemispherical-nosed projectile and b) flat-nosed projectile. 
This analysis further elucidates the complexity of the interaction between an impacting projectile and material with a post-weld residual stress field; however, the results clearly show that the adverse effect of the associated plastic strain damage accumulated during the welding process and the distribution of this strain field - is the dominant factor.

\section{Conclusions}

In this paper, the effect of post-weld residual stress and associated plastic damage on the ballistic performance of austenitic steel plate was studied. Numerical simulations of hemisphericalnosed and flat-nosed projectiles impacting on a welded plate were conducted via finite element analyses, using a Johnson-Cook material model and the shear failure fracture criterion, which takes into account the initial weld-induced plastic strain. It was found that the post-weld plastic damage had an adverse effect on the predicted ballistic performance of the target. Predictions of the ballistic performance using the shear failure fracture criterion capture the expected adverse effects of post-weld plastic damage. The present results suggest that for an accurate numerical solution, a material model with a fracture criterion that considers the pre-existing plastic damage of the target is required, particularly when studying the impact of welded structures. Furthermore, the numerical analyses show that flat-nosed projectiles penetrate easier than hemispherical-nosed projectiles under all circumstances. This phenomenon may be attributed to the perforation mechanism of rounded projectiles (i.e. ductile hole growth), which requires more energy to push the material aside by plastic work. Finally, comparison of weld-side and back-face impact predictions implies that the concentration of weld-induced plastic damage on the weld side is likely to reduce the ballistic performance when back-face impacts are considered, due to damage-assisted material failure as the projectile exits the target. This orientation-dependent ballistic performance, which suggests weldside impact scenarios are preferable for welded plate, also highlights the importance of the plastic damage distribution in welded structures for ballistic studies.

\section{Acknowledgements}

The authors would like to thank Dr Mike C Smith from EDF Energy Nuclear Generation for many helpful discussions regarding weld modelling.

\section{References}

[1] M.T. Hutchings, P.J. Withers, T.M. Holden, T. Lorentzen, Introduction to the Characterization of Residual Stress by Neutron Diffraction, CRC Press, Boca Raton, 2005.

[2] W.-S. Ryu, W.G. Kim, K.Y. Lee, Evaluation of creep crack growth behaviour of Type 316LN stainless steel, Transactions of the 17th International Conference on Structural Mechanics in Reactor Technology (SMiRT 17), Prague, Czech Republic, 2003, pp. F05-4.

[3] M. Kobayashi, T. Matsui, Y. Murakami, Mechanism of creation of compressive residual stress by shot peening, Int. J. Fatigue 20 (1998) 351-7.

[4] C.J. Lammi, D.A. Lados, Effects of residual stresses on fatigue crack growth behavior of structural materials: Analytical corrections, Int. J. Fatigue 33 (2011) 858-67.

[5] M.A.S. Torres, H.J.C. Voorwald, An evaluation of shot peening, residual stress and stress relaxation on the fatigue life of AISI 4340 steel, Int. J. Fatigue 24 (2002) 877-86.

[6] G.M. Reddy, T. Mohandas, Influence of welding process and residual stress on ballistic performance, J. Mater. Sci. Lett. 15 (1996) 1633-5.

[7] R.V. Martins, NeT - Task Group 4: Three-Pass Slot Weld Specimen in Austenitic Stainless Steel. Protocole for the Destructive and Non-Destructive Determination of Residual Stress in ThreePass Slot Weld Specimens in Austenitic Stainless Steel, Network on Neutron Techniques Standardisation for Structural Integrity, Report Version 3.3, Petten, The Netherlands, 2009. 
[8] Abaqus Analysis User’s Manual (Version 6.9), SIMULIA, 2008.

[9] O. Muransky, P.J. Bendeich, M.C. Smith, O. Kirstein, L. Edwards, T.M. Holden, Analysis of residual stresses in three-pass slot weld (NeT-TG4): finite element modelling \& neutron diffraction, Proceedings of the ASME 2010 Pressure Vessels and Piping Conference, PVP2010-25290 Seattle, USA, 2010, pp. MF-4-2.

[10] M.C. Smith, A.C. Smith, NeT bead-on-plate round robin: Comparison of residual stress predictions and measurements, Int. J. Press. Vessels Pip. 86 (2009) 79-95.

[11] R.M. Smith. FEAT-WMT: Weld-Modelling Tool User Guide, FP/CR/0029/09, Rev. 2.0.0, FeatPlus Limited, 2010.

[12] J.L. Chaboche, A review of some plasticity and viscoplasticity constitutive theories, Int. J. Plast. 24 (2008) 1642-93.

[13] J. Lemaitre, J.-L. Chaboche, Mechanics of Solid Materials, Cambridge University Press, 1994.

[14] R.V. Martins, C. Ohms, K. Decroos, Full 3D spatially resolved mapping of residual strain in a 316L austenitic stainless steel weld specimen, Mater. Sci. Eng., A 527 (2010) 4779-87.

[15] G.R. Johnson, W.H. Cook, A constitutive model and data for metals subjected to large strains, high strain rates and high temperatures, Proceedings of the 7th International Symposium on Ballistics, The Hague, The Netherlands, 1983, pp. 541-7.

[16] G.R. Johnson, W.H. Cook, Fracture characteristics of three metals subjected to various strains, strain rates, temperatures and pressures, Engineering Fracture Mechanics 21 (1985) 31-48.

[17] S. Dey, T. Børvik, O.S. Hopperstad, J.R. Leinum, M. Langseth, The effect of target strength on the perforation of steel plates using three different projectile nose shapes, Int. J. Impact Eng. 30 (2004) 1005-38.

[18] M.C. Smith, A.C. Smith, NeT - Task Group 4: Finite Element Simulation Protocol, Network on Neutron Techniques Standardisation for Structural Integrity, Report Issue 1, EDF Energy Nuclear Generation, Gloucester, United Kingdom, 2009.

[19] H. Nordberg, Note on the sensitivity of stainless steels to strain rate, Research Report No 04.01, AvestaPolarit Research Foundation and Sheffield Hallam University, 2004.

[20] D.W. Zhou, W.J. Stronge, Ballistic limit for oblique impact of thin sandwich panels and spaced plates, Int. J. Impact Eng. 35 (2008) 1339-54.

[21] S. Dey, T. Børvik, X. Teng, T. Wierzbicki, O.S. Hopperstad, On the ballistic resistance of double-layered steel plates: An experimental and numerical investigation, Int. J. Solids Struct. 44 (2007) 6701-23. 